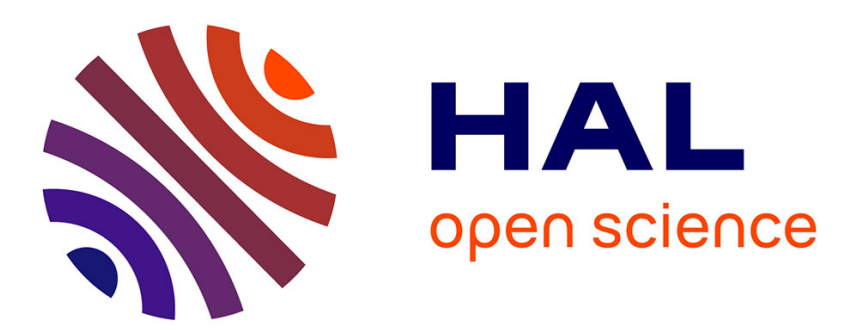

\title{
Influence of velocity on the human global postural strategies during the movement leading up to the vertical upside-down position
}

Philippe Nouillot, Françoise Natta

\section{- To cite this version:}

Philippe Nouillot, Françoise Natta. Influence of velocity on the human global postural strategies during the movement leading up to the vertical upside-down position. Neuroscience Letters, 2004, 363, pp.224-228. hal-01828761

\section{HAL Id: hal-01828761 \\ https: / hal-insep.archives-ouvertes.fr/hal-01828761}

Submitted on 3 Jul 2018

HAL is a multi-disciplinary open access archive for the deposit and dissemination of scientific research documents, whether they are published or not. The documents may come from teaching and research institutions in France or abroad, or from public or private research centers.
L'archive ouverte pluridisciplinaire HAL, est destinée au dépôt et à la diffusion de documents scientifiques de niveau recherche, publiés ou non, émanant des établissements d'enseignement et de recherche français ou étrangers, des laboratoires publics ou privés. 


\title{
Influence of velocity on the human global postural strategies during the movement leading up to the vertical upside-down position
}

\author{
Philippe Nouillot ${ }^{\text {a,b }}$, Françoise Natta ${ }^{c, *}$ \\ ${ }^{a}$ Laboratoire STAPS, Université Paris 12, 94000 Créteil, France \\ ${ }^{\mathrm{b}}$ Laboratoire de Physiologie du Mouvement, Université Paris-Sud, 91405 Orsay, France \\ ${ }^{\mathrm{c}}$ Laboratoire MAP, INSEP, 75012 Paris, France \\ * Corresponding author. Tel.: +33-1-41-74-44-27. E-mail address: francoise.natta@insep.fr
}

(Article publié dans : Neuroscience Letters, 2004, 363, pp. 224-228)

\begin{abstract}
The aim of this study was to examine the influence of the velocity on the control of the final postural equilibrium in the movement of standing up into upside-down vertical posture on the hands. Seven expert gymnasts performed the movement on a force plate of large dimensions from which the kinematic of center of mass (CoM) was studied. The first result showed that the speed of CoM was increased in the vertical axis but did not change in the antero-posterior axis. The second result showed a reduction of the duration of the anticipatory postural adjustments (APA) conversely to the speed. This was in contrast to the movements performed in the natural erect stance. These results suggest firstly that the speed of CoM corresponds to a global strategic response linked to the body's posturo-kinetic capacity, and secondly that the reduction of the APA seems to be linked to the precariousness of the final equilibrium.
\end{abstract}

Keywords: Anticipatory postural adjustments; Balance; Biomechanical parameters; Motor strategy 
When a voluntary movement is carried out, it is well established that postural adjustments generally appear before its initiation. In segmental movements performed in the upright stance, the local (segmental) and global (acceleration of center of mass (CoM), ground reaction, center of pressure $(\mathrm{CoP}))$ anticipatory postural adjustments (APA) vary with the parameters of intentional movement, such as the localization, inertia and velocity [2,11].APA also depend on the stability of equilibrium. In the erect postural stance, when the postural base is more unstable, either because of the reduced support area $[1,21]$ or owing to a movable support surface [8], the APA are increased. According to the hypothesis proposed by Bouisset and Zattara [3] that the dynamic of the intentional movement is a perturbation to postural equilibrium, the APA, which are dynamic phenomena, serve to minimize the subsequent postural destabilization. In the upper segmental ('focal chain') movements, the initial postural base, characterized by the support area and the 'postural chain', remains the same.

In movements with body progression the APA serve moreover to create appropriate global dynamics, allowing the displacement of the CoM, such as in step or gait initiation [6], and in lower limb elevation or flexion $[9,15,20]$. In these movements the duration and amplitude of anticipatory global postural dynamics increase with the speed of movement. However, in certain cases: (1) when the movement is performed under global mechanical constraints, such as the CoP magnitude in the initiation of step, although the speed varies, APA can remain the same [12]; (2) when the equilibrium state is too precarious, the APA can be absent [19]. In this last case, it was hypothesized that this absence of APA can correspond to another strategic response of the central nervous system (CNS) [1]. The global dynamic strategy can also change with speed. For example, in lower leg flexion, when the movement is performed very slowly, the direction of the horizontal ground reaction force under the stance leg is reversed [20]. In the movements with body progression, when the postural base is continuously changing, as in locomotion, after the loss of balance, the CoM must be continuously in motion, whereas in lower limb movements, in which the postural base is transitorily changing, the CoM's speed must be stopped and balance restored. In these latter movements, horizontal speed can be considered as a factor responsible for the greater difficulty in controlling the final balance. Indeed, in erect stance in the quasi static equilibrium on the floor, the gravitational line must be projected inside the support area, according to the concept of 'CoM position limits'. On the other hand, when the CoM is in horizontal movement before the final stance, the concept of 'CoM velocity-position limits', proposed by Pai and Patton [20], must then be used. This concept is grounded on the 'functional' aspect of the support area, which is reducing conversely 
with the speed of movement. Therefore, in movement with body progression, when the speed of $\mathrm{CoM}$ is increasing, it can considered that the final balance is more precarious.

In acrobatic sports, there are numerous tasks with transient postural bases in which the final balance is more precarious than in the upright stance. This is the case when a gymnast is standing on his hands on the floor after a reverse movement. Compared to the normal standing posture, the supporting plane is smaller, and the forearm muscles are likely less strong. In this kind of movement, the final postural balance can be compared to an inversed pendulum $[7,19]$. The aim of this study was to answer the following question: which global motor strategies are involved in movement in which final balance is particularly precarious?

Seven subjects, all expert gymnasts, five men and two women from 17 to 22 years (mean age $19.2 \pm 2.2$ years), participated in the experiment with their full consent. They performed an acrobatic movement from an initial posture with both hands and feet on the ground (Fig. 1). The hands were placed on the lateral axis, flat on the ground. Feet were placed along the anteroposterior axis, one in front of the other so that the rear lower limb was straight and the front one flexed. The corresponding task was to place the body in an upside-down posture. The final posture, in equilibrium on the hands, had to be held for 1-2 s. The aim of the task was, after an auditory signal, to raise up the body on the hands by projecting the straight lower limb, and pushing on the ground with the flexed limb. This projection was considered as the onset of intentional movement $(\mathrm{t} 0)$ and was determined from a mono-axial accelerometer placed on the heel. For each test the subject repositioned the feet and hands in the same place. Two experimental conditions were considered, distinguished by the velocity: (1) natural velocity (normal condition: NV); (2) fast velocity (FV), i.e. as fast as possible. About ten tests per condition had to be performed. Between each trial, the subjects had a short rest. For safety reasons, an operator was positioned in front of the subject so as to retain him in case there was a dorsal imbalance, leading to a fall or a hand movement. The interest in this kind of movement concerns the initial stand base, particularly wide (in quadruple stance), and the final stand base, particularly narrow (manual stance).

As in a previous paper [17] the method of analysis was based on data exploitation from a force plate of large dimensions, so that the subjects could have the four supports on it without the force plate being a constraint. From the force plate, which displayed the CoP and the ground reaction forces, the global dynamics applied to the CoM were obtained, according to Newton's laws. The biomechanical variables taken into account in our results were accelerations of the $\mathrm{CoM}$ and speeds obtained by simple integration of accelerations (Euler's method) on the 
antero-posterior $\left(x^{\prime \prime}, x^{\prime}\right)$ and vertical $\left(z^{\prime \prime}, z^{\prime}\right)$ axes. The acquisition of data was realized with a period of sampling rate of $750 \mathrm{~Hz}$. The statistic methods used were t-test and paired t-test. The significant differences were considered when $\mathrm{P}<0: 05$. Concerning the performance, i.e. the speed of CoM, according to the order given to subjects the peaks of speed showed greater values in FV than NV, but only on the vertical axis (Table 1). Indeed, whereas speed values were about $16 \%$ greater on the vertical axis, they were similar for the two conditions on the antero-posterior axis.

Concerning the description of the task from mechanical traces, the first variations of traces (t-1, Figs. 1 and 2) occurred systematically before the onset of intentional movement ( $t 0$ ), which was at the time of the break-down observed on the traces, generally on the anteroposterior axis (see Table 2). This corresponded to the onset of a purely postural phase, i.e. to a global APA (APA phase). Before t 21 there was no variation of the traces, corresponding to a period of motor latency when the subject remained motionless (motionless phase). Between t0 an $\mathrm{t} 1$ the subject was on three supports, the two hands and one foot, the rear foot being up from the floor. The body was turning upside down. Therefore, during this phase as the CoM was only forwards accelerated, and simultaneously the displacement of the CoP backwards directed, we can consider that the subject was pushing backwards on the floor with the flexed limb (pushing phase). From t-1 to t1, which is the sum of the APA and pushing phases, on the antero-posterior axis (x) the variation of the acceleration was forwards directed, and simultaneously the CoP backwards directed (amplitudes of displacement: between $57 \pm 16$ and $359 \pm 19 \mathrm{~mm}$ ). This period corresponds to a propulsive phase. In the same time, the vertical acceleration (z) was generally upwards directed (systematically for five subjects). However, during the APA phase vertical acceleration was slightly downwards directed only for two subjects. For the anteroposterior and vertical acceleration traces there were one or two peaks, depending on the subject. The individual variations on the two axes have been more precisely described in a preliminary study [17]. At t1, the CoM was beginning to be backwards and downwards accelerated, which corresponds to an onset of a breaking phase along both the axes. Consequently, from this time the speeds of the CoM were reducing. This time can be considered as the take-off of the front foot. The subject was then only on his hands. The period from tl to the end of CoM displacement corresponds to a tilting phase.

Concerning the durations, the comparison between the two experimental conditions showed that they were significantly shorter in FV for all phases (Table 2). The differences were about $23 \%$ in the APA phase on the antero-posterior axis and about $28 \%$ on the vertical axis, about 
$27 \%$ in the body turning phase on the antero-posterior axis and about $37 \%$ on the vertical axis, and about $26 \%$ in the body propulsive phase on both the antero-posterior and vertical axes.

Concerning the peak magnitudes of the acceleration, phases must be separately considered (Table 2). For the APA phase, on the antero-posterior axis, peaks were significantly greater in FV than in NV. In this axis five subjects presented positive peaks, and two subjects presented negative peaks. However, for these two categories of subjects the comparison of the peaks between the two experimental conditions was also significantly different. For the group of five subjects see Table 2. For the two other subjects, differences were $\mathrm{P}=0.001$ for the first subject and $\mathrm{P}=0.02$ for the second subject (t-test). For the pushing phase on the antero-posterior axis, there was no difference between FV and NV, whereas on the vertical axis peaks were greater in FV than NV.

The purpose of this study was to examine the influence of the velocity on the global postural organization. In the movement of standing up into an upside-down posture, we were interested by the dynamic phases preceding the initiation of the intentional movement, i.e. to APA, as well as the phase of execution, which precedes the tilting movement towards the final balance position of the body. Concerning the speed of movement, subjects had to perform the movement with a spontaneous velocity, and as fast as possible. In the FV condition, the speed of CoM was significantly increased compared to the NV. What is particularly interesting is that speed varied only on the vertical axis. The equilibrium problems must therefore be considered separately on each axis.

On the vertical axis, it had been hypothesized in a preliminary study of a lower limb flexion performed in erect stance that it was not necessary to preserve equilibrium [18]. For example, the body segments are stacked up and all the vertical displacements of the CoM remain above the support area, i.e. they do not change the gravity line projection contrary to an anteroposterior displacement.

On the antero-posterior axis, the control of body balance should depend upon the posturokinetic capacity (PKC) of the body system to minimize the postural destabilization [4]. However, the PKC is lower on this axis compared to the vertical axis, as has been shown in normal erect stance. Displacements are limited by the support area, the muscle forces, and the possible joint mobilizations $[13,14]$. Results of studies have shown that dynamic variations depend on the axis. In a study of a forearm flexion performed in erect stance, it was reported by Friedli et al. [10] that on the antero-posterior axis the acceleration created by the voluntary 
movement at the elbow level was considerably reduced at the feet stance level, whereas on the vertical axis the acceleration was totally transmitted. Thus, according to the hypothesis that a greater speed of theCoM reduces the 'functional' support area, we can assume that the CNS 'chooses' to conserve a spontaneous speed which perhaps corresponds to an 'optimal' and/or a maximal value, i.e. in particular compatible with the PKC of the neuromuscular system.

Concerning both the APA duration and amplitude, whilst amplitudes of mechanical traces were increasing with the speed, the durations were decreasing. This result is likely to depend on the specificity of tasks. In segmental movements, the aim of the APA is to counteract in advance the perturbation due to the forthcoming voluntary movement in order to maintain the initial postural equilibrium [2]. In the initiation of gait the dynamic of movement is created using gravity. The greater the speed of CoM, the longer the time the gravity action acts, because gravity is a constant value. It has been demonstrated by Brenière et al. [6] that the horizontal speed of CoM was a programmed parameter. In the sprint start, in which initial posture is similar to the task of raising up on the hands, the increasing APA durations are linked firstly to the forthcoming antero-posterior speed and secondly eventually to the stand up on the feet, i.e. against gravity [16]. Although in our study the movement was also performed against gravity, the antero-posterior speed must be stopped, contrary to the sprint start. As the antero-posterior speed remained similar and the vertical speed was greater, the reduction of durations is therefore not linked to the reduction of the speed. This reduction of durations does not depend on the instability of initial balance which is obviously very stable, or on the initial global mechanical constraints [12]. The APA reduction seems to be linked to the precariousness of the final balance. Indeed, according to the impulsion law $\left(\sum F \Delta t=m \Delta V\right.$, with initial velocity $=0$, because the subject was initially motionless), when the magnitude of the antero-posterior reaction force was increasing, the reduction of duration allowed the conservation of the 'optimal' speed. This dynamical strategy occurs during the pushing phase, which follows the APA phase. Therefore, as suggested by Bouisset et al. [5], the duration seems a parameter particularly sensitive to the postural condition.

During the pushing phase, a braking activity assumed by the upper limbs (which are postural limbs) was probably exerted. This assumption is relayed on the tilting phase traces, which follows the pushing phase, and on results from the dynamic of the postural lower limb in the study of lower limb flexion [21]. However, this upper limb breaking activity should be more important during the pushing phase in FV, as global magnitude values remained similar (Table 3). 
To sum up, according to a previous study, in which Do et al. [9] had shown that final balance was a programmed parameter, from our results we can confirm that the greater or lesser stability of the final balance was a determining factor of the motor program. In our study, a specific global dynamic strategy was to increase the body speed only on the vertical axis, on which final balance, in terms of CoM position limits, does not exist. This strategy was characterized by a reduction of the APA duration, contrary to other studies in which APA were increasing with speed of movement. The global dynamic strategy has been allowed on the grounds of the postural stance characteristics during the body propulsive phase.

\section{References}

[1] A.S. Aruin, W.R. Forrest, M.L. Latash, Anticipatory postural adjustments in conditions of postural instability, Electroenceph. clin. Neurophysiol. 109 (1998) 350-359.

[2] S. Bouisset, M. Zattara, Anticipatory postural movements and dynamic asymmetry, in: V.S. Gurfinkel, M.E. Ioffe, J. Massion, J.P. Roll (Eds.), Stance and Motion. Facts and Concepts, Plenum, New York, 1988, pp. 177-183.

[3] S. Bouisset, M. Zattara, Segmental movement as a perturbation to balance? Facts and concepts, in: J.M. Winters, S.L.Y. Wood (Eds.), Mutiple Muscles Systems: Biomechanics and Movement Organization, Springer Verlag, New York, 1990, pp. 498-505.

[4] S. Bouisset, M.C. Do, M. Zattara, Posturo-kinetic capacity assessed in paraplegics and parkinsonians, in: M. Woollacott, F. Horak (Eds.), XIth International Symposium of the Society for Postural and Gait Research, Posture and Gait: Control Mechanisms, II, University of Oregon Books, Eugene, OR, 1992, pp. 19-22.

[5] S. Bouisset, J. Richardson, M. Zattara, Are amplitude and duration of anticipatory postural adjustments identically scaled to focal movement parameters in human? Neurosci. Lett. 278 (2000) 153-156.

[6] Y. Brenière, M.C. Do, S. Bouisset, Are dynamic phenomena prior to stepping essential to walking? J. Mot. Behav. 19 (1987) 62-76.

[7] G. Clément, D. Rézette, Motor behavior underlying the control of an upside-down vertical posture, Exp. Brain Res. 59 (1985) 478-484. 
[8] P.J. Cordo, L.M. Nashner, Properties of postural movements related to a voluntary movement, J. Neurophysiol. 47 (1982) 287-303.

[9] M.C. Do, P. Nouillot, S. Bouisset, Is balance or posture at the end of voluntary movement programmed? Neurosci. Lett. 130 (1991) 9-11.

[10] W.G. Friedli, L. Coen, M. Hallett, S. Stanhope, S.R. Simon, Postural adjustments associated with rapid voluntary arm movements. II. Biomechanical analysis, J. Neurol. Neurosurg. Psychiatry 51 (1988) 232-243.

[11] F.B. Horak, P.E. Esselman, M.E. Anderson, M. Lynch, The effects of movement velocity, mass displaced and task certainty on associated postural adjustments made by normal and hemiplegic individuals, J. Neurol. Neurosurg. Psychiatry 47 (1984) 1020-1028.

[12] T. Ito, T. Azuma, N. Yamashita, Anticipatory control in the initiation of a single step under biomechanical constraints in humans, Neurosci. Lett. 352 (2003) 207-210.

[13] A.D. Kuo, F.E. Zajac, A biomechanical analysis of muscle strength as a limiting factor in standing posture, J. Biomech. 26 (Suppl. 1) (1993) 137-150.

[14] G. McCollum, T.K. Leen, Form and exploration of mechanical stability limits in erect stance, J. Mot. Behav. 21 (1989) 225-244.

[15] L. Mouchnino, J. Massion, Séquence posturo-cinétique pendant l'élévation d'une jambe: timing des événements et effets de l'entraînement, in: M. Laurent, J.F. Marini, R. Pfister, P. Therme (Eds.), Recherches en APS, 3, Editions Actio, Paris, 1992, pp. 1-7.

[16] F. Natta, Y. Brenière, C. Réga, Le départ de sprint en starting-blocks: analyse des mouvements anticipateurs de la course, Arch. Intern. Physiol. Biochim. 99 (6) (1990) C121C122.

[17] P. Nouillot, Caractérisation dynamique d'un mouvement acrobatique: le renversement en appui tendu sur les mains, Sci. Mot. 32-33 (1998) 102-105.

[18] P. Nouillot, M.C. Do, S. Bouisset, Are there anticipatory segmental adjustments associated with lower limb flexions when balance is poor in humans? Neurosci. Lett. 279 (2000) 77-80. 
[19] Y.C. Pai, J. Patton, Center of mass velocity-position predictions for balance control, J. Biomech. 30 (4) (1997) 347-354.

[20] M. Rogers, Y.C. Pai, Dynamic transitions in stance support accompanying leg flexion movements in man, Exp. Brain Res. 81 (1990) 398-402.

[21] M. Zattara, S. Bouisset, Posturo-kinetic organization during upper limb movement performed from varied foot positions, Neurosci. Lett. 22 (1987) 1969.

Table 1 Speed values of the CoM

\begin{tabular}{|l|l|l|l|}
\hline & NV $($ mean \pm SD $)$ & FV $($ mean \pm SD $)$ & P value (t-test, $\mathbf{n}=7)$ \\
\hline $\mathrm{x}^{\prime}\left(\mathrm{ms}^{-1}\right)$ & $0.74 \pm 0.12$ & $0.77 \pm 0.14$ & NS \\
\hline $\mathrm{z}^{\prime}\left(\mathrm{ms}^{-1}\right)$ & $0.89 \pm 0.16$ & $1.06 \pm 0.17$ & $<0.001$ \\
\hline
\end{tabular}

Values correspond to the maximum speed magnitude $(\mathrm{m} / \mathrm{s})$ of the CoM along the anteroposterior ( $\left.\mathrm{x}^{\prime}\right)$ and vertical ( $\left.\mathrm{z}^{\prime}\right)$ axes. NV, FV, movement performed respectively in natural and in fast velocity. The comparison between the two conditions is performed with the t-test. 
Table 2 Kinematic durations

\begin{tabular}{|l|c|c|c|}
\hline \multicolumn{1}{|c|}{ Phases } & NV (mean \pm SD) & FV (mean \pm SD) & P value (t-test, $\mathbf{n}=\mathbf{7})$ \\
\hline APA phase (1) & & & \\
\hline $\mathrm{X}^{\prime \prime}(\mathrm{ms})$ & $-333 \pm 53$ & $-257 \pm 54$ & $<0.03$ \\
\hline $\mathrm{Z}^{\prime \prime}(\mathrm{ms})$ & $-318 \pm 67$ & $-230 \pm 61$ & $<0.03$ \\
\hline Pushing phase (2) & & & $<0.04$ \\
\hline $\mathrm{X}^{\prime \prime}(\mathrm{ms})$ & $336 \pm 75$ & $246 \pm 67$ & $<0.03$ \\
\hline $\mathrm{Z}^{\prime \prime}(\mathrm{ms})$ & $330 \pm 61$ & $208 \pm 105$ & $<0.01$ \\
\hline Propulsive phase (1+2) & & & $<0.02$ \\
\hline $\mathrm{X}^{\prime \prime}(\mathrm{ms})$ & $665 \pm 116$ & $490 \pm 86$ & \\
\hline $\mathrm{Z}^{\prime \prime}(\mathrm{ms})$ & $627 \pm 127$ & $467 \pm 72$ & \\
\hline
\end{tabular}

The values correspond to the durations of the different phases. APA phase (1): duration between the first variations of mechanical traces ( $\mathrm{t}-1)$ and the onset of intentional movement $(\mathrm{t} 0)$. The negative sign indicates that durations are before t0. Pushing phase (2): duration between the onset of intentional movement (t0) and the take-off of the front foot from the floor (t1). Propulsive phase: duration between the first variations of mechanical traces (t 21$)$ and the take-off of the front foot from the ground (t1). This last phase corresponds to the sum of the absolute values $(1+2) \cdot x^{\prime \prime}, z^{\prime \prime}$ : forwards and upwards accelerations of CoM, respectively. NV, $\mathrm{FV}$, movement performed in natural and in fast velocity, respectively. Mean (of subjects) and standard deviations (SD) are expressed in milliseconds. 
Table 3 Differences of kinematic magnitudes between NV and FV

\begin{tabular}{|l|l|l|l|l|}
\hline Phases & NV (mean \pm SD) & FV $($ mean \pm SD) & FV - NV (mean \pm SD) & P value (paired t-test) \\
\hline APA phase & & & & \\
\hline$x^{\prime \prime}\left(\mathrm{ms}^{-2}\right)$ & $1.45 \pm 0.99$ & $2.72 \pm 1.40$ & $1.19 \pm 0.64$ & $<0.01^{\mathrm{a}}$ \\
\hline $\mathrm{z}^{\prime \prime}\left(\mathrm{ms}^{-2}\right)$ & $1.16 \pm 0.54$ & $2.51 \pm 0.84$ & $1.35 \pm 0.39$ & $<0.01^{\mathrm{b}}$ \\
\hline Pushing phase & & & & \\
\hline $\mathrm{x}^{\prime \prime}\left(\mathrm{ms}^{-2}\right)$ & $2.49 \pm 1.07$ & $2.60 \pm 1.63$ & $0.11 \pm 0.61$ & $\mathrm{NS}^{\mathrm{a}}$ \\
\hline $\mathrm{z}^{\prime \prime}\left(\mathrm{ms}^{-2}\right)$ & $3.66 \pm 1.05$ & $5.87 \pm 1.87$ & $2.21 \pm 1.28$ & $<0.01^{\mathrm{a}}$ \\
\hline
\end{tabular}

APA phase: duration between the first variations of mechanical traces $(\mathrm{t}-1)$ and the onset of intentional movement ( $\mathrm{t} 0$ ). Pushing phase: duration between the onset of intentional movement (t0) and the take-off of the front foot from the ground. $x^{\prime \prime}, z^{\prime \prime}$, forward and upward accelerations of CoM, respectively. The comparisons between the two conditions were performed with the paired t-test $\left({ }^{\mathrm{a}} \mathrm{n}=7,{ }^{\mathrm{b}} \mathrm{n}=5\right)$. 


\section{Figure 1.}

Representation of the postural characteristics of the task. The task is characterized by three times: $t-1$ corresponds to the onset of biomechanical variations; to corresponds to the take-off of the rear foot from the floor; $t 1$ corresponds to the take-off of the front foot from the floor.
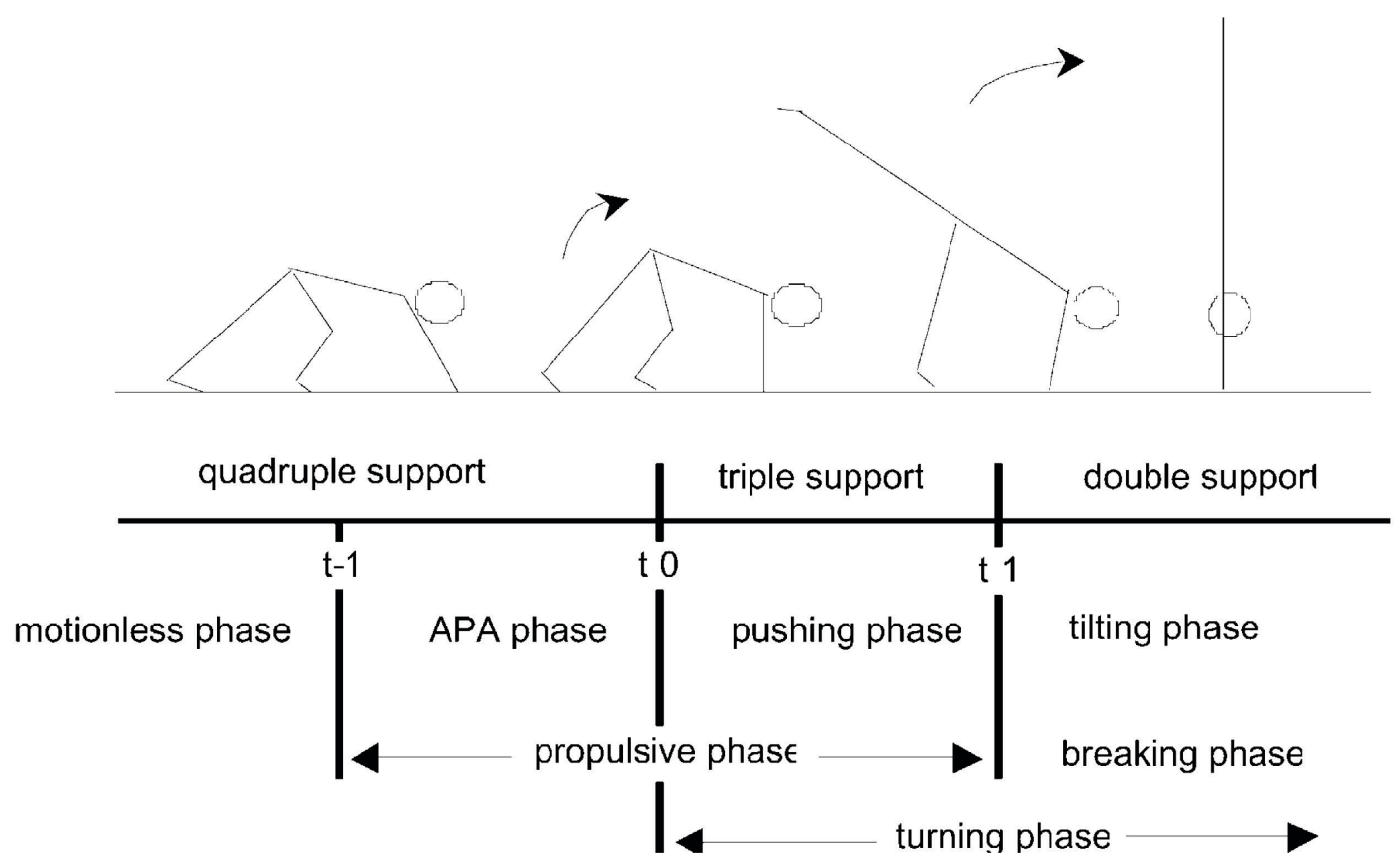
Figure 2.

These mechanical traces represent the acceleration and the speed of the CoM (one trial) along the antero-posterior axis (respectively: $x^{\prime \prime}$ and $x^{\prime}$ ) and the vertical axis (respectively: $z^{\prime \prime}$ and $z^{\prime}$ ) for the same subject. Directions of trace variations. $f$ and $b$, forwards and backwards; $u$ and $d$, upwards and downwards. to is the initiation of intentional movement, $t-1$ is the onset of the postural dynamic, and $t 1$ is the take-off of the front foot; the subject is only on his hands. Left, NV: movement performed in natural velocity; right, FV: movement performed in fast velocity.

NV

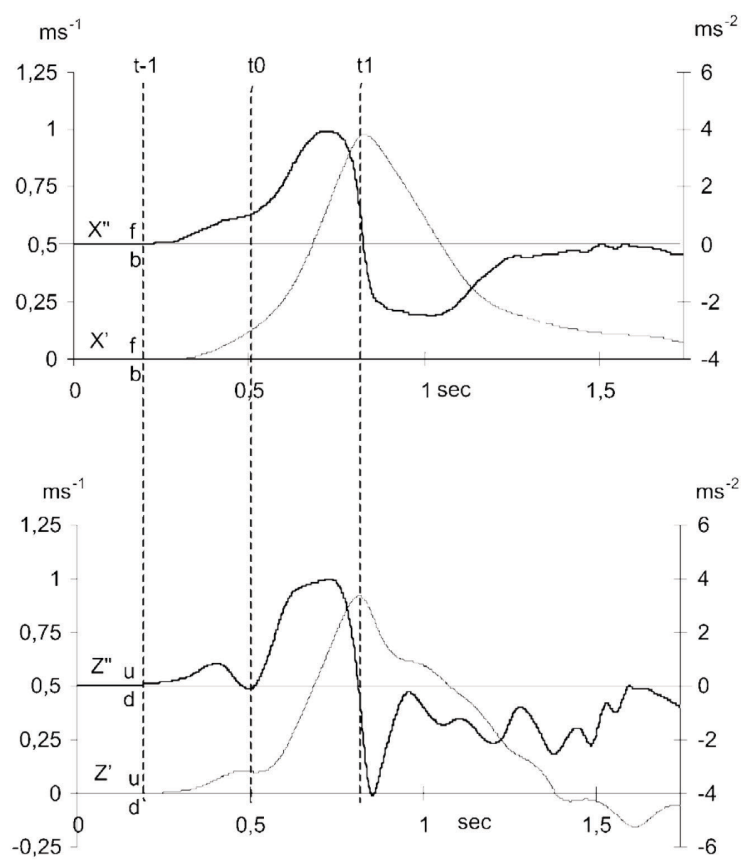

FV

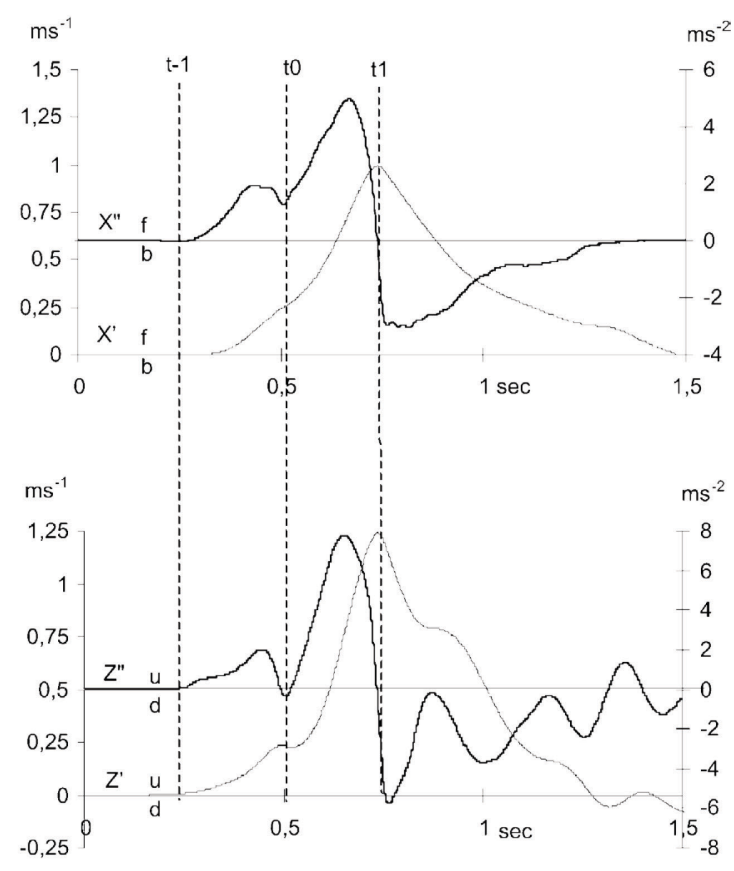

